\title{
Untangling Constructs on Characteristics of Effective Teaching from a Higher Education Institution: Basis for Effective Teaching Program
}

\author{
Djonde Frega Antiado \\ Southville International School and Colleges, Ras Al Khaimah, United Arab Emirates \\ https://orcid.org/0000-0001-5597-1339 \\ Maher Ibrahim Mikhael Tawadrous \\ City University College of Ajman, Sheikh Ammar Road, United Arab Emirates \\ https:// orcid.org/0000-0003-3420-1428 \\ Rommel Pilapil Sergio \\ Abu Dhabi School of Management, Sheikh Zayed Bin Sultan Street, United Arab Emirates \\ https:// orcid.org/0000-0002-2058-9495
}

\begin{abstract}
The need of skilled workforce to meet the challenges of the 21st century puts teaching effectiveness to the forefront of higher education policies. Therefore, the current study explores the Characteristics of Effective Teaching (CET) as observed by the students from a higher education institution in the United Arab Emirates. The study employed a descriptive survey method wherein qualitative analysis of data was used. The respondents $(\mathrm{N}=199 ; 121$ were females and 78 were males) are registered in General Education courses using a pre-constructed interview schedule. The 69 CETs had been ascertained by qualitative method through axial coding of general themes in order to come-up with recommendations pointing to Effective Teaching Program (ETP). The dominant characteristics of effective teaching as perceived by the student respondents were 21 items with "helpful" topping the list, followed by "knowledgeable," "friendly," "organized," and "flexible." Six classifications were derived from clustering the CET, namely: buddy type, accommodating type, cool type, academician type, techie type, and non-biased type. The major findings reveal that the three important elements of effective teaching as perceived by students are academic qualification, attitudes, and skills. Specific recommendations to ETP are also introduced in the paper to strengthen the quality of teaching effectiveness.
\end{abstract}

Keywords: Characteristics of effective teaching; Effective teaching program; Student's perception 


\section{Introduction}

Today's students are described as belonging to the "digital generation." They are constantly exposed to digital technology and electronic devices such as computer games and other virtual media which serve as their learning tools. They are accustomed to a "plug-and-play" learning approach. The divergent and dynamic learning orientation of this generation requires hands-on experience and, learning by trial and error or exploration, as opposed to the traditional sequential or linear learning approach followed by traditional universities. Students have evolved into active learners brought about by an open learning environment with the accessibility of the internet where information is delivered to anyone, any time, and any place. In addition to the rapid changes of technology, the influence of globalization or internationalism of education, diversity of students, global competition and the need of skilled workforce to meet the challenges of the $21^{\text {st }}$ century, puts teaching effectiveness to the forefront of higher education policies. Faced with a challenging scenario, new paradigms for quality teaching are prescribed to prepare graduates to work and adapt in a complex and fast changing environment. An effective teacher is the one who can respond to these changes and meet the learning needs of students of the $21^{\text {st }}$ century. In this regard, an interesting inquiry should be raised; how do we characterize effective teachers in the $21^{\text {st }}$ century?

In response to the challenges of the $21^{\text {st }}$ century, three main areas of competency that teachers should develop were identified in a report by the National Institute of Education, Singapore (2009), which are: (1) literacies on the use of knowledge and information (ability to show adeptness in guiding students to access information through various electronic and print media critically, creatively and accurately, and develop the students' ability to use knowledge to generate better ideas); demonstrate skill in utilizing multiple media or interactive modes of instruction to facilitate learning; and demonstrate awareness of cultural diversity (or multicultural literacy); (2) ability to enhance and expand the learning environment utilizing varied instructional tools, technologies and resources to broaden students' awareness and knowledge of current and real issues affecting their own community and world contexts; and (3) ability to integrate technology in pedagogy and curriculum by devising innovative, inquiry and problem-based approaches and developing higher order thinking skills of students.

A vital element of effective teaching also entails having desirable personal characteristics or personality dispositions. The study of Calderhead (2008) indicated that in both educational settings (traditional or online), personality traits significantly correlated with effective teaching (the two variables were found to have significant linear relationship). Personal characteristics had been found to be of paramount importance in effective teaching, more than content knowledge, cultural knowledge, and pedagogical knowledge (Spitzer, 2009). It is an influencing factor affecting student achievement and needs further attention and investigation (Chandler, 2015; Cioli-Stewart 2014), and it contributes to a conducive learning environment by facilitating and / enhancing learning (CiolliStewart, 2014; Halder, 2014; Kimbrough-Walls, 2012). More than that, student's perception of "good or bad teacher" is based on the personal characteristics observed in class which impact on students' assessment of teaching effectiveness (Ibad, 2018). 
As we transform and meet the demands of the $21^{\text {st }}$ century education, we need not only to focus on what to teach, rather we need to think how to impart and develop the needs of our $21^{\text {st }}$ century learners. The latter requires finding out how we can be effective in our teaching which starts with identifying dispositional characteristics. As a starting point, the researchers explored the perspective of students from a private higher education institution in the United Arab Emirates (UAE) to find out constructs of characteristics on effective teaching.

\section{Literature Review}

The following body of information points to the literature review that has direct resemblance on the study.

\subsection{Teacher Effectiveness}

Elliott (2010) identifies two sub-topics related to teaching effectiveness: "effective teacher characteristics may be summarized as measuring who I am or the essence of teaching, whereas teacher effectiveness may be summarized as what I do or the process/product of teaching (p.1)." In a review of related studies on teacher effectiveness and student outcomes by Burroughs et al. (2019), it was pointed out that teacher characteristics and behaviors (observed by students during classroom instruction and delivery of content to support learning) influenced the students' achievement or outcome the most. Findings of Teven and McCroskey, and Connell on caring as a teacher attribute (as cited in Chandler, 2015) indicated that if students perceived that their teacher cares, the more care they show in class and learn more as evidenced by higher achievement scores. A study on comparing high performing and low performing schools was conducted, and findings show a significant relationship between teaching effectiveness to students' attendance and academic performance (Etim, Etim \& Blizard, 2020). In another context, Mohammaditabar et al. (2020) described effective teachers as possessing exemplary human qualities with an expertise in teaching. Apparently, the personality dimension is perceived as a key factor in teaching effectiveness. Since learners are not pedagogically literate, students tended to give more importance to personality rather than professionalism to characterize effective teaching (Mohammaditabar et al., 2020). In a study involving teachers' perceptions of effective teaching, professionalism in terms of being competent, having the expertise, qualification and knowledge were highly prioritized (Rasool, 2017).

Teaching effectiveness can be deduced from the perceived profound or lasting impact on the students. Gender and year of study influenced students' perception of effective teachers. In this vein, Yilmaz (2011) conducted a study in which he asked students pursuing teacher training students to describe the characteristics of teachers whom they characterized as effective throughout their schooling from primary, secondary or university level. Results showed that a significant number of the respondents found their high school teachers as most "effective" compared to their elementary or university teachers. The defining factor of "effectiveness" had been based on how the teachers had contributed to students' personality development - dealing with life challenges or outlook in 
life, thoughts and emotions, having confidence in one's worth (self-esteem) and being self-sufficient. In terms of gender and years of study, Yilmaz (2011) found that female students tended to report having effective teachers more than the male students; and more students during their first year of study or during freshmen revealed that they have had at least an effective teacher.

The concept of what made a teacher effective depended on the thinking styles of students. However, the teaching style that encouraged creative thinking and complex information processing was considered the most effective teaching style among students (Li-Fang, 2004; Skliar, 2014). The same characteristics of effective teaching were found in an online environment and traditional face-toface settings, yet the emphasis or order of importance was different (Delaney, Johnson \& Treslan, 2010; Gangi, 2011). The factors or variables which contribute to successful teaching ranked according to importance are: (1) Personal knowledge and characteristics (ability to collaborate with colleagues, forms strong relationships with students, etc); (2) Content knowledge (knowledge about what is to be learned or taught); (3) Cultural knowledge (understanding of cultural context and characteristics of learners in belonging to a particular culture); and (4) Pedagogical knowledge (general knowledge how to teach) (Spitzer, 2009, p.88). The ability to communicate well, being concerned for student learning, ability to motivate students and course organization were found to be significant criteria of teaching effectiveness (Young and Shaw, 1999). In addition, effective teachers did not necessarily get high ratings on all these important variables implying that teaching effectiveness does not follow an additive model. Further, students who were made to understand the value or worth of a course indicated the strongest predictor of teacher effectiveness (Young and Shaw, 1999).

\subsection{Students' Perception of Characteristics of Effective Teachers}

From a western perspective, Delaney et al. (2010) conducted a study to find students' perceptions of effective teaching in higher education comparing oncampus and distance modes of delivery. Regardless of the mode of delivery, nine characteristics of effective teaching were identified with differences in emphasis: Respectful, Knowledgeable, Approachable, Engaging, Communicative, Organized, Responsive, Professional, and Humorous.

Being respectful is ranked the first for both on-campus and distance modes of delivery. The students described respectful as being fair, realistic, understanding, trustworthy, flexible, humble, caring, empathetic, patient, kind, helpful, consistent, compassionate, open-minded, reasonable, sincere, concerned and diplomatic. Being knowledgeable is demonstrated as being practical, flexible, current, competent, credible, eclectic, qualified, and reflective. Being positive, friendly, happy, personable, helpful, and accessible was characterized as approachable. The students approached engaging as being assertive, enthusiastic, energetic, interesting, interactive, passionate, stimulating, motivating, charismatic, creative, and positive. Being communicative is demonstrated as attentive, clear, constructive, understandable, and thorough to one's student. To be organized, a teacher should be prepared, efficient and focused, and being perceptive, efficient, helpful, accommodating, and available 
described what responsive meant. To be professional, one has to be confident, dedicated, hygienic, punctual, efficacious and dependable; and humorous as being kind, has a positive outlook, engaging and approachable. Most attributes of effective teachers mainly fall into two categories, namely: teaching skills and personality characteristics (Toraman, 2019).

It is significant to note that student-teacher relationship had been found significantly important in students' academic performance and learning experience. If students perceived that their needs and/ wants are met as a result of the teacher's positive level of engagement, it followed an increment of students' grades, and overall satisfaction of the course (Boluda \& Lopez, 2021). Besides, the "emotional connection" established between the student and the teacher had been found crucial in teaching effectiveness (Batool et al., 2015). The student' perception characterizing effective teaching using content analysis (Batool et al., 2015), included qualities as: the teachers' friendliness, cooperativeness, politeness, empathy, dedication, preparedness in class, being considerate of the students' level of learning and, capable of encouraging and motivating students to participate.

A cross-cultural study comparing the qualities of good teachers in China asserted that results are consistent with US studies in spite of different categories found (Liu and Meng, 2009). Three categories that mark an effective teacher as perceived by Chinese students were: (1) teacher ethics, (2) professional skills, and (3) test scores. A teacher that demonstrates high teacher ethics is the one who is responsible, treats students' equally, caring, maintains friendly and close relations with students, humorous, considerate, and able to control temper. Also, the one who is knowledgeable, has excellent teaching skills and able to create active classroom atmosphere is perceived as high in professional skills. If students get good test scores, then a teacher is considered effective.

\subsection{Characteristics of Effective Teaching in Arab Countries}

There are three important dimensions which were identified in line with teaching effectiveness: academic characteristics, social and psychological characteristics of personality, and practical and pedagogical expertise. These were found to characterize effective ESL (English as a Second Language) teachers among Qatari female college students (Sabah, 2018). To begin with, students expected that highly effective ESL teachers who rated high on academic characteristics, achieved the basic skills and required teacher qualifications or pursued graduate degree, attended relevant training and showed teaching proficiency, and at the same time able to speak the students' native language. In terms of social and psychological characteristics, the students regarded the following as highly important: being friendly, just or fair, kind, shows stability under pressure and stimulates learning, good listener, polite and respectful, reduces students' anxiety in class, encouraging and able to motivate students, patient, shows willingness to help students in and out the class, shows flexibility in checking attendance, firm in dealing with students and gives five or less assignments. Teachers who highly demonstrated practical and pedagogical expertise applied various strategies in teaching, were well prepared, managed the class and class time properly, and prepared activities that stimulated the 
interest of students, and utilizes technology (such being familiar with the use software, multi-media, social media) in teaching.

Among Turkish college students, perception of effective teachers had been based on teacher's personal and professional characteristics (Yilmaz, 2011). In order of preference, the top ten (10) characteristics or qualities of effective teachers include: (1) exhibiting dynamism, (2) shows empathy, (3) has expertise on the subject area, (4) shows warmth and friendliness, (5) fair to students, (6) communicates effectively, (7) motivates and inspires students, (8) has the sense of humor and makes learning fun, (9) well informed and updated on relevant issues, and (10) promotes the talents of students. Another study (Cakmak, 2009) involving Turkish prospective teachers (college students), identified important behaviors which described effective teaching characteristics as follows: states the objectives of the lesson; keeps students lively in the lesson; fond of the job performed; teaches with regard to students' interests and talents, and able to maintain rapport with students. The least important of the behaviors of an effective teacher cover: arranges various seating arrangements (group, etc.) in the teaching process; jokes with students; requires students to do presentations (projects, etc.) in lessons; suggests a source material list to students to adhere to in the lessons and the tendency to be authoritative.

Teaching effectiveness is perceived as a combination of personality and ability, wherein the former is being regarded as a key factor. Findings from the research conducted by Raymond (2008) uncovered that students from Middle East regions primarily considered five highly important personality traits of an effective teacher namely: (1) being respectful, (2) making classes interesting, (3) fairness in grading and evaluating student work, (4) cares that students succeed in the course, and (5) being friendly to students. Three important ability attributes were found to describe excellent teaching which were: (1) being able to encourage students' questions and discussion, (2) well prepared and organized, and (5) able to make difficult subjects easy to learn. Add to this, an effective teacher is the one who can establish and/ maintain good rapport and shows flexibility and willingness to compromise or adjust depicting UAE culture. Two themes, namely: interpersonal rapport with students and instructional skills were found to characterize perceived qualities of effective teaching among college students in UAE (Saafin, 2008). Using content analysis, the qualities and practices which were identified in order of frequency were; (1) treats students with respect, (2) shows flexibility and willingness to compromise, (3) being helpful and caring, (4) friendly, (5) has a sense of humor, (6) helps students understand by exhausting all possible means for students to learn, (7) gives the students a chance to speak and ask questions, (8) shows dedication in teaching, (9) fair or treats students equally in class, (10) a role model, (11) knowledgeable or has mastery of courses taught, (12) patient, and (13) smiles often.

Based on the synopsis presented on the characteristics of effective teaching, the following implications are put forward: 
1. Perceptions on effective teaching are multidimensional and do not follow a "one size fits all" perspective, however effective teaching impacts on positive learning experiences and quality of education in general.

2. The personality characteristics and behaviors of teachers as perceived by students are important dimensions in the teaching learning process of effective teaching, and needs further study.

3. The global landscape of education is rapidly changing and as a result, roles of teachers and expectations of students change which could create a gap for students to relate effectively with their teachers and vice-versa.

4. Conducting periodic study of students' perceptions of effective teaching should be made in order to design responsive educational programs geared towards addressing their specific needs.

5. How students perceive effective teaching characteristics across cultures merit further exploration.

6. A limited number of studies had been conducted, especially in the Middle East.

Therefore, the current study aimed to introduce baseline data of information to add value to existing literature and to serve as a reference data of information for future research.

\section{Objectives of the Study}

This qualitative, descriptive study aimed to explore the concept of effective teaching of students from a private higher education institution in the United Arab Emirates. It aims to specifically meet the following research objectives:

1. To know the dominant Characteristics of Effective Teaching (CET) as perceived by students.

2. To determine the elements that comprise the concept of CET by the students.

3. To recommend a set of programs for effective teaching.

\section{Research Paradigm}

Figure 1 shows the process paradigm of the study.

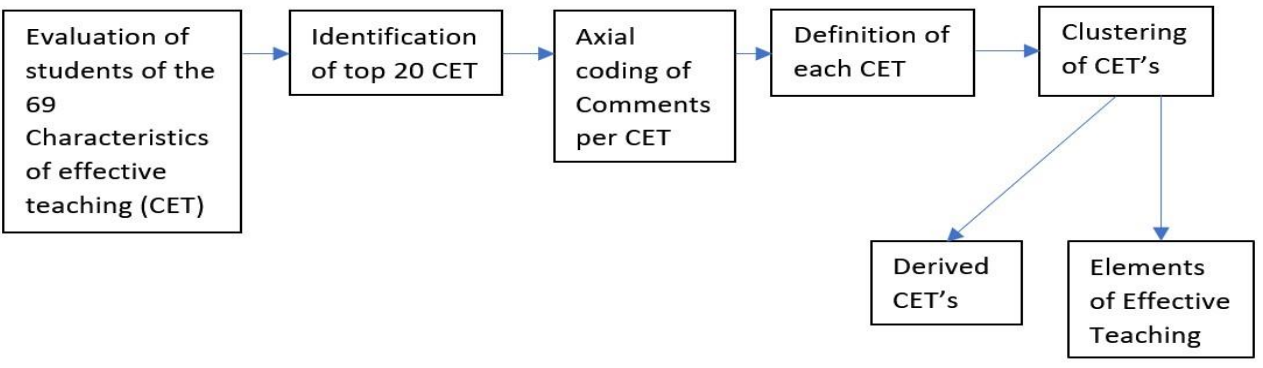

Figure 1: The process paradigm of the study

The paradigm (Fig.1) displays the entire process of the qualitative study. In determining the dominant Characteristics of Effective Teaching (CTE), mean rating per CET was computed and the top 20 CETs. Comments for the 20 CETs 
were gathered for analysis. Then, Axial Coding was done to provide an abstract of the definition per CET. The first part of the coding was established to determine whether the comments are clear definitions of the CET or otherwise. Thus, "Definition" and "Unclear" were coded accordingly. Second coding was done among the comments which were coded as definition. Thematic clustering was used as the basis for coding. Comments with the same theme were given the same code and were further clustered to come-up with the derived CETs and with the elements of Effective Teaching.

\section{Methodology, Sampling and the Study Setting}

The paper employed qualitative research design, particularly the descriptive study utilizing the interview method. The process of content analysis has been employed through axial coding and clustering of responses to come up with specific constructs on characteristics of effective teaching. The accessibility sampling technique was employed from which all the students registered in the General Education Program were invited to be a part of the study. Accordingly, a total of one hundred ninety-nine (199) students voluntarily participated in this study, of which one hundred twenty-one (121) were females, and seventy-eight (78) were males. The study was conducted in a private university of the United Arab Emirates (UAE).

\section{Data Gathering Tools}

Each of the 199 respondents was separately asked through an interview session, facilitated by the authors of this research paper. Students were given assurance that their identity is withheld as part of the ethical practice. The respondents were given a pre-constructed list of characteristics of effective teaching (Table 1). After which, they were asked to choose five (5) characteristics of effective teaching from the list given and rank these 5 items in order of importance (using the range 1 being the most important and 5 being the least important). Thereafter, the respondents were asked to describe the characteristics they chose. The descriptions of students were taken into account and were tabulated. The top five (5) most important characteristics from a list of sixty-nine (69) characteristics of effective teaching (CET) were ascertained through content analysis (axial coding and clustering of CETs).

\section{Results and Discussion}

The results were derived from the collected data of 199 respondents after the necessary treatments that had been conducted. The treatment of data was based on the objectives presented in this study, in which the first objective aims to know the dominant characteristics of effective teaching as perceived by students. The CETs were chosen based on the top five generated responses from the respondents. The 20 CETs were generated from the coding and framing of student responses through the interviews conducted personally by the authors themselves. Table 1 below shows the CETs with their corresponding ranks based on the frequency distribution. 
Table 1. Dominant characteristics of effective teaching (CET) as perceived by the students

\begin{tabular}{|c|c|c|}
\hline CETs & $\mathbf{N}$ & Rank \\
\hline Helpful & 67 & 1 \\
\hline Knowledgeable & 65 & 2 \\
\hline Friendly & 63 & 3 \\
\hline Organized & 39 & 4 \\
\hline Flexible & 37 & 5 \\
\hline Understanding & 29 & 6.5 \\
\hline Respectful & 29 & 6.5 \\
\hline Open minded & 27 & 8 \\
\hline Fair & 25 & 9 \\
\hline Understandable & 22 & 11 \\
\hline Motivating & 22 & 11 \\
\hline Happy & 22 & 11 \\
\hline Communicative & 20 & 13 \\
\hline Interesting & 19 & 15 \\
\hline Clear & 19 & 15 \\
\hline Professional & 19 & 15 \\
\hline Qualified & 15 & 17 \\
\hline Focused & 14 & 18 \\
\hline Available & 12 & 19 \\
\hline Humorous & 11 & 20.5 \\
\hline Patient & 11 & 20.5 \\
\hline
\end{tabular}

The result of the analysis for Objective 1 shows that being "helpful" is the most dominant characteristic among the top 21 CETs considered. Fourteen out of the top CETs corroborated the studies of Sabah (2018) and Saafin (2008) using Arab students as respondents. These characteristics include helpful, knowledgeable, friendly, flexible, respectful, fair, understanding, motivating, communicative, interesting, clear, professional, qualified and patient.

As can be gleaned from Table 1, the first five CETs fall under the category of Personal Knowledge and Characteristics (Spitzer, 2009). The factors or variables which contribute to successful teaching according to importance are: (1) Personal knowledge and characteristics (ability to collaborate with colleagues, forms strong relationships with students, among others), (2) Content knowledge (knowledge about what is to be learned or taught), (3) Cultural knowledge (understanding of cultural context and characteristics of learners in belonging to a particular culture), and (4) Pedagogical knowledge (general knowledge how to teach). 
As for the second objective which aims to determine the elements that comprise the concept of effective teaching, the following table displays the gathered data.

Table 2. Clustered elements that comprise the concept of effective teaching

\begin{tabular}{|c|c|c|}
\hline $\begin{array}{c}\text { Academic } \\
\text { Qualifications }\end{array}$ & Attitude & Skill \\
\hline $\begin{array}{l}\text { Professional } \\
\text { Knowledgeable } \\
\text { Qualified }\end{array}$ & $\begin{array}{l}\text { Flexible } \\
\text { Understanding } \\
\text { Communicative } \\
\text { Focused } \\
\text { Understandable } \\
\text { Clear } \\
\text { Open Minded } \\
\text { Helpful }\end{array}$ & $\begin{array}{l}\text { Flexible } \\
\text { Understanding } \\
\text { Communicative } \\
\text { Focused } \\
\text { Understandable } \\
\text { Clear } \\
\text { Open Minded } \\
\text { Helpful }\end{array}$ \\
\hline & $\begin{array}{l}\text { Respectful } \\
\text { Friendly } \\
\text { Happy } \\
\text { Patient } \\
\text { Available } \\
\text { Fair }\end{array}$ & $\begin{array}{l}\text { Knowledgeable } \\
\text { Motivating } \\
\text { Interesting } \\
\text { Professional } \\
\text { Humorous } \\
\text { Organized }\end{array}$ \\
\hline
\end{tabular}

Table 2 shows the initial clustering resulted to three elements that comprise the concept of effective teaching. These are Academic Qualifications, Attitudes, and Skills. It is significant to note that there are 14 equal number of characteristics in attitudes and skills, and the first 8 of which have exactly the same order elements. An academically qualified instructor who is perceived as effective in teaching is the one who has $\mathrm{PhD}$, relevant training/s and/ certification related to the field of study, imparts lessons clearly and able to relate to student's experiences, and adept in the use of technology to enhance learning. In terms of attitude, the one who demonstrates flexibility, is fair, shows respect and patience, maintains a happy demeanor, accessible when needed, at the same time able to deliver lessons clearly, sensitive to the diverse needs and/ address learning difficulties of students is qualified as an effective teacher. Teaching skills that students perceived important as: able to effectively communicate and establish good rapport to keep students engaged and motivated in learning, students are able to openly share their opinions and values, shows expertise subject area and professional by being updated in the use of technology; able to recognize and address diverse needs of students (different abilities and cultural backgrounds).

Data on objective 3 which aims to recommend a set of programs for effective teaching, strongly outlined the following:

1. Faculty Development. Faculty should be given the time, venue and/ opportunity to reflect on their methods, their delivery, and the way they connect with their students. Through diagnostic meetings and appropriate workshops, they would be able uncover those weaknesses, further enhance their strengths and come up with courses of action to improve their effectiveness in teaching. 
2. Faculty Recruitment. The elements that comprised the concept of CET to include academic qualifications, attitude and skills should be considered in the recruitment of faculty.

3. Student Feedback. Consider students' concept of effective teaching in coming up with tools in evaluating Effective Teaching of Instructors at least in an annual basis.

4. Faculty Evaluation. Evaluate further effective teaching in the university using the behavioral manifestations of the characteristics of effective teaching as perceived by students.

5. Data Analytics. Compare effective teaching concepts of faculty, and administrators with the concept of students as basis for leveling of expectations.

6. Model Development. Consider the derived model together with other models in the development of faculty evaluation tool.

7. Teacher Education. Develop competencies to address diverse needs of students (different abilities and cultural backgrounds); and continuously enhance training on the use of current technology in learning and teaching.

\section{Conclusion}

Limited studies had been conducted in the Arab region on effective teaching. Finding out how to impart and develop the need of the 21st century learners is deemed important. Hence, this study sought to identify CETs which can provide baseline data for further exploration and/ for future research. Twenty-one items of the 69 CETs were perceived as essential among the research informants. Fourteen items out of the 21 CETs corroborated with the studies conducted among Arab students. These characteristics include the notion of being helpful, knowledgeable, friendly, flexible, respectful, fair, understanding, motivating, communicative, interesting, clear, professional, qualified and patient. Results also indicated that students tended to describe CETs based on the perceived personality characteristics or traits of the teacher followed by professional characteristics. The results align with the findings of recent research conducted. Thus, how the teachers' CETs influence the learning and teaching process need further study. The ability to "connect" with students to make their learning conducive or promote their desire to learn had been perceived as relevant. Further, the use of information and communication technologies for teaching had been considered as vital for effective teaching. There were 6 classifications derived from clustering the CETs, namely: buddy type, accommodating type, cool type, academician type, techie type, and non-biased type and finding out which of these types influences the teaching learning process, an area that needs further study. The elements that comprised the concept of CETs by the students were as follows: academic qualifications, attitude, and skills. These elements need to be considered in designing programs for faculty recruitment, development, and evaluation. 
The study had been limited to students taking general education courses. Thus, it is recommended that further exploration ought to be made of students taking specialization courses.

\section{Acknowledgments}

The authors express their sincerest gratitude to the editors and blind reviewers who have shared their expertise and guidance for the opportunity laid through this paper.

\section{Funding Information}

This article is not financially supported by any funding agency.

\section{Declaration of Conflicting Interests}

The author declared no potential conflicts of interest with respect to the research, authorship, and/or publication of this article.

\section{References}

Batool, S. S., Naz, B., Habib, S., Anjum, W., Goraya, F., Akram, M., Khalid, A., \& Sadaf, A. (2015). Construction of Effective Teaching Evaluation Scale and Students' Perception of the Characteristics of Effective Teachers. Pakistan Journal of Social and Clinical Psychology, 13(1), 28-35.

Boluda, I. K., \& López, N. V. (2021). A teachers' orientation approach to understand the university teacher-student relationship. Estudios Sobre Educación, 40, 149-172. http://dx.doi.org/10.15581/004.40.149-172

Burroughs, N., Gardner, J., Lee, Y., Guo, S., Touitou, I., Jasen, K., \& Schmidt, W. (2019). Teaching for excellence and equity. Switzerland: Springer, Cham. https://doi.org/10.1007/978-3-030-16151-4_2

Cakmak, M. (2009). Prospective teachers' thoughts on characteristics of an "effective teacher". Education and Science, 34(153).

Calderhead, S. A. (2008). College students' perceptions of effective teaching personality traits: A quantitative analysis of traditional versus online education [Doctoral dissertation]. Capella University, United States. https://www.learntechlib.org/p/117120/

Ciolli-Stewart, S. (2014). An investigation into the traits of and strategies used by highly effective teachers. https:/ / search.proquest.com/docview/1654779644?accountid=145382

Chandler, W. B. (2015). The potential influence a teacher's personality has on student valueadded results. https:// search.proquest.com/docview/1733667441?accountid=145382

Delaney, J. G., Johnson, A., Johnson, T. D., \& Treslan, D. (2010). Students' perceptions of effective teaching in higher education. http://research.library.mun.ca/id/eprint/8370

Elliott, B. L. S. (2010). Effective teacher characteristics: A two nation causal comparative study. https:// search.proquest.com/docview/250956002?accountid=145382

Etim, J. S., Etim, A. S., \& Blizard, Z. D. (2020). Teacher effects, student school attendance and student outcomes: Comparing low and high performing schools in North Carolina. Educational Research Quarterly, 44(2), 47-81. https://search.proquest.com/scholarly-journals/teacher-effects-student-schoolattendance $/$ docview $/ 2470411952$ / se-2?accountid $=145382$ 
Gangi, S. (2011). Differentiating instruction using multiple intelligences in the elementary school classroom: A literature review [Doctoral dissertation]. University of Wisconsin--Stout.

Halder, S., \& Dutta, R. (2014). Exploring the relationship between teacher effectiveness and personality traits. International Journal of Education and Management Studies, $4(4), 249-254$.

Ibad, F. (2018). Personality and ability traits of teachers: Student perceptions. Journal of Education and Educational Development, 5(2), 162-177. http://dx.doi.org/10.22555/joeed.v5i2.2215

Kimbrough-Walls, V. (2012). Students' perception of important teaching behaviors in classroom and clinical environments of a community college nursing and dental hygiene education https:/ / search.proquest.com/docview/1024141591?accountid=145382

Li-Fang, Z. (2004) Thinking styles: University students' preferred teaching styles and their conceptions of effective teachers. The Journal of Psychology, 138(3), 233-252. https://doi.org/10.3200/JRLP.138.3.233-252

Liu, S., \& Meng, L. (2009). Perceptions of teachers, students and parents of the characteristics of good teachers: A cross-cultural comparison of china and the united states. Educational Assessment, Evaluation and Accountability, 21(4), 313-328. http://dx.doi.org/10.1007/s11092-009-9077-z

Mohammaditabar, M., Bagheri, M. S., Yamini, M., \& Rasaee, M. E. (2020). Qualities of a Good English Language Teacher from the Perspectives of Textbook Authors in the Field of Language Teaching, Teachers, and Learners. The Qualitative Report, 25(11), 3927-3960. https://search.proquest.com/scholarly-journals/qualitiesgood-english-language-teacher/docview / 2465477496/se-2?accountid=145382

Rajandiran, D. (2020). Singapore's Teacher Education Model for the 21st Century (TE21). In F.M Rrimers (Ed.), Implementing Deeper Learning and 21st Education Reforms (pp. 59-77). Springer, Cham. doi:10.1007/978-3-030-57039-2_3

Rasool, G., Mahboob, U., Sajid, M. \& Ahmad, S. (2017). Characteristics of effective teaching: A survey on teacher's perceptions. Pakistan Oral \& Dental Journal, 37(1). https://search.proquest.com/scholarly-journals/characteristics-effectiveteaching-survey-on/docview/1891291525/se-2?accountid=145382

Raymond, S. M. (2008). Effective $\mathcal{E}$ ineffective university teaching from the students' and faculty's perspectives: Matched or mismatched expectations? [Doctoral dissertation] University of Exeter. https://ore.exeter.ac.uk/repository/bitstream/handle/10036/40767/Raymond S.pdf? sequence $=1$

Sabbah, S. S. (2018). The Characteristics of effective English as a second language instructors. International Journal of English Language Teaching, 6(2), 1-24. http://www.eajournals.org/wp-content/uploads/Tertiary-Level-

Students\%E2\% 80\%99-Perceptions-of-the-Characteristics-of-Effective-English-asa-Second-Language-Instructors.pdf

Saafin, S. (2008). Arab tertiary students' perceptions of effective teachers. Learning and Teaching in Higher Education: Gulf Perspectives, 5(2). http://www.zu.ac.ae/lthe/lthe05_02_02_saafin.htm

Skliar, O. (2014). Native and nonnative English-speaking teachers in Turkey: Teacher perceptions and student attitudes [Doctoral dissertation]. Middle East Technical University, Ankara, Turkey. https:// tez. yok. gov. tr/UlusalTezMerkezi

Spitzer, L. (2009). Personality or pedagogy: Which personal characteristics are necessary for ESL teachers to possess and what role do they play compared to formal pedagogical training in ESL teaching?. Studies in Learning, Evaluation, Innovation $\mathcal{E}$ Development, 6 (3), 80-92. 
Toraman, Ç. (2019). Effective teacher characteristics. Asian Journal of Instruction, 7(1), 114.

Yilmaz, A. (2011). Quality problem in teaching profession: Qualities teacher candidates feel to be required of teachers. Educational Research and Reviews, 6(14), 812-823.

Young, S., \& Shaw, D. G. (1999). Profiles of effective college and university teachers. The Journal of Higher Education, 70(6), 670-686. doi:10.1080/00221546.1999.11780803

\section{Appendices}

Appendix 1. Pre-Constructed Characteristics of Effective Teaching Used in the Interview Schedule

\begin{tabular}{|c|l|l|l|l|l|}
\hline 1 & Approachable & 24 & Challenging & 47 & Creative \\
\hline 2 & Enthusiastic & 25 & Practical & 48 & Realistic \\
\hline 3 & Available & 26 & Energetic & 49 & Compassionate \\
\hline 4 & Knowledgeable & 27 & Thorough & 50 & Professional \\
\hline 5 & Stimulating & 26 & Helpful & 51 & Qualified \\
\hline 6 & Personable & 29 & Attentive & 52 & Pleasant \\
\hline 7 & Humorous & 30 & Eclectic & 53 & Hygienic \\
\hline 8 & Understanding & 31 & Efficient & 54 & Accommodating \\
\hline 9 & Flexible & 32 & Accessible & 55 & Reasonable \\
\hline 10 & Understandable & 33 & Prepared & 56 & Consistent \\
\hline 11 & Open Minded & 34 & Confident & 57 & Perceptive \\
\hline 12 & Communicative & 35 & Friendly & 58 & Kind \\
\hline 13 & Punctual & 36 & Trustworthy & 59 & Interactive \\
\hline 14 & Responsive & 37 & Positive & 60 & Focused \\
\hline 15 & Sincere & 38 & Empathic & 61 & Charismatic \\
\hline 16 & Concerned & 39 & Dedicated & 62 & Efficacious \\
\hline 17 & Organized & 40 & Current & 63 & Credible \\
\hline 18 & Interesting & 41 & Dependable & 64 & Assertive \\
\hline 19 & Patient & 42 & Caring & 65 & Passionate \\
\hline 20 & Fair & 43 & Engaging & 66 & Diplomatic \\
\hline 21 & Motivating & 44 & Happy & 67 & Reflective \\
\hline 22 & Clear & 45 & Constructive & 68 & Humble \\
\hline 23 & Respectful & 46 & Competitive & 69 & Collaborative \\
\hline
\end{tabular}

Based on Delaney, J., Johnson, A., Johnson, T.D. \& Treslan, D. (2010). Students' Perceptions of Effective Teaching in Higher Education, p. 20. (http://www.uwex.edu/disted/conference/Resource_library/handouts/28251_10 $\underline{\text { H.pdf) }}$

Appendix 2. Top 20 Obtained Characteristics of Effective Teaching as defined by the Students using the Axial Coding Sequence

\begin{tabular}{|c|c|}
\hline Characteristics & $\begin{array}{c}\text { Behavioral Manifestations of Instructors as Described by } \\
\text { Students }\end{array}$ \\
\hline
\end{tabular}

\begin{tabular}{|l|l|}
\hline Helpful & $\begin{array}{l}\text { Instructors take initiative to ask students of anything they missed } \\
\text { or failed to understand. } \\
\text { Instructors answer all queries from students in and out of their } \\
\text { classroom. Instructors make sure that students understand the } \\
\text { lessons in class. } \\
\text { Instructors encourage students to do their best. } \\
\text { Instructors assist students even with non-academic purposes. }\end{array}$ \\
\hline
\end{tabular}




\begin{tabular}{|c|c|}
\hline & $\begin{array}{l}\text { Instructors prepare students in facing what is in store for them in } \\
\text { the field of work. } \\
\text { Instructors provide bonus questions to help students increase their } \\
\text { grades. }\end{array}$ \\
\hline Knowledgeable & $\begin{array}{l}\text { Instructors have PhDs. Instructors are proficient in the use of } \\
\text { English as a medium of instruction in class. } \\
\text { Instructors are confident with facts of their lesson because of } \\
\text { their use of several references like books and personal } \\
\text { experiences. } \\
\text { Instructors are confident in explaining their lesson with the use } \\
\text { of technologies. }\end{array}$ \\
\hline Friendly & $\begin{array}{l}\text { Instructors find time to greet, converse and play jokes with } \\
\text { students even outside the classroom. } \\
\text { Instructors create a family working environment inside the } \\
\text { classroom. } \\
\text { Instructors find time to help students understand the lesson } \\
\text { even outside the classroom. } \\
\text { Instructors smile in and outside the classroom. }\end{array}$ \\
\hline Organized & $\begin{array}{l}\text { Instructors see to it that instructional materials are guided by } \\
\text { the arrangement of topics in the course syllabus. } \\
\text { Instructors make sure that materials are reader friendly. } \\
\text { Instructors present topics using a certain flow of information } \\
\text { that is easily understandable to students. }\end{array}$ \\
\hline Flexible & $\begin{array}{l}\text { Instructors can manage and change schedules in class } \\
\text { accordingly. Instructors are not strict with absences and "late } \\
\text { incurrence" of students in class. } \\
\text { Instructors explain requirements and quizzes ahead of time, } \\
\text { then, provides additional help to students when needed. } \\
\text { Instructors can use practical approaches in teaching when } \\
\text { needed. Instructors provide means on how students can reach } \\
\text { them when needed. }\end{array}$ \\
\hline Understanding & $\begin{array}{l}\text { Instructors exert effort to understand and adjust to the } \\
\text { limitations of students. } \\
\text { Instructors find time to know personal concerns of students } \\
\text { even outside their classroom. }\end{array}$ \\
\hline Respectful & Instructors respect religion and culture of every student. \\
\hline Open Minded & $\begin{array}{l}\text { Instructors can discuss any topic and accepts any answers from } \\
\text { students. } \\
\text { Instructors recognize differences in abilities and cultures and } \\
\text { adjust accordingly }\end{array}$ \\
\hline Fair & $\begin{array}{l}\text { Instructors give grade that is due to students based on their } \\
\text { works not on nationality. } \\
\text { Instructors properly supervise students to provide appropriate } \\
\text { grade. Instructors provide instructional materials to } \\
\text { everybody. }\end{array}$ \\
\hline Understandable & $\begin{array}{l}\text { Instructors use a language that is understandable to all } \\
\text { students. Instructors accent do not affect students } \\
\text { understanding of the lesson. } \\
\text { Instructors make themselves available for questions from } \\
\text { students even outside their classes. }\end{array}$ \\
\hline
\end{tabular}




\begin{tabular}{|c|c|}
\hline Motivating & Instructors bring out the best in every student. \\
\hline Happy & Instructors come to class in good mood and with all smiles. \\
\hline Communicative & $\begin{array}{l}\text { Instructors are available whenever students would like to } \\
\text { communicate with them. } \\
\text { Instructors are capable of indulging students to participate in } \\
\text { exchanging information through discussion in and even } \\
\text { outside the class. } \\
\text { Instructors use several means to communicate with students } \\
\text { like SMS, webmail, and portal. }\end{array}$ \\
\hline Clear & $\begin{array}{l}\text { Instructors exert effort in making sure that students understand } \\
\text { each lesson, requirements, policies and exams clearly. } \\
\text { Instructors see to it that students know how to communicate } \\
\text { with them whenever they have questions even outside their } \\
\text { classes. }\end{array}$ \\
\hline Professional & $\begin{array}{l}\text { Instructors are educated with higher degree and teaches } \\
\text { subjects from their own field. } \\
\text { Instructors present lessons in a simple manner with the use of } \\
\text { technologies. }\end{array}$ \\
\hline Qualified & $\begin{array}{l}\text { Instructors teach subjects in their field of specialization and } \\
\text { shows evidence that they are studying or learning subjects } \\
\text { outside their specialization. } \\
\text { Instructors do have high qualifications like PhDs and degrees } \\
\text { of specialization. }\end{array}$ \\
\hline Focused & $\begin{array}{l}\text { Instructors are grounded with their mission to develop each } \\
\text { student. } \\
\text { Instructors exert effort in simplifying lessons for maximum } \\
\text { understanding of students. }\end{array}$ \\
\hline Available & $\begin{array}{l}\text { Instructors are anywhere in the university when needed by } \\
\text { students. Instructors are willing to render service in the } \\
\text { absence of the other. } \\
\text { Instructors delegates tasks in his absence. }\end{array}$ \\
\hline Humorous & $\begin{array}{l}\text { Instructors exert effort to break the seriousness of the class by } \\
\text { giving jokes and funny comments. }\end{array}$ \\
\hline Patient & $\begin{array}{l}\text { Instructors entertain many questions from students and is not } \\
\text { irritated when students come to class late or when students } \\
\text { leave the room. }\end{array}$ \\
\hline
\end{tabular}

Appendix 3. Classification of Characteristics Derived from the Combination of the CETs as Perceived by the Students Using Axial Coding

A. Buddy Type

\begin{tabular}{|l|l|}
\hline Characteristics & \multicolumn{1}{c|}{ Behavioral Manifestations } \\
\hline Available & Instructors are accessible in the university when needed by students. \\
\hline Flexible & Instructors provide means on how students can reach them when needed. \\
\hline Communicative & $\begin{array}{l}\text { Instructors are available whenever students would like to communicate } \\
\text { with them. } \\
\text { Instructors use several means to communicate with students like SMS, } \\
\text { webmail, and portal. }\end{array}$ \\
\hline Clear & $\begin{array}{l}\text { Instructors see to it that students know how to communicate with them } \\
\text { whenever they have questions even outside their classes. }\end{array}$ \\
\hline Understanding & $\begin{array}{l}\text { Instructors make themselves available for questions from students even } \\
\text { outside their classes. }\end{array}$ \\
\hline
\end{tabular}




\begin{tabular}{|l|l|}
\hline Helpful & $\begin{array}{l}\text { Instructors answer all queries from students in and out of their classroom. } \\
\text { Instructors take initiative to ask students of anything they missed or failed } \\
\text { to understand. }\end{array}$ \\
\hline
\end{tabular}

\section{B. Accommodating Type}

\begin{tabular}{|l|l|}
\hline \multicolumn{1}{|c|}{ Characteristics } & \multicolumn{1}{c|}{ Behavioral Manifestations } \\
\hline Friendly & $\begin{array}{l}\text { Instructors find time to help students understand the lesson even outside the } \\
\text { classroom. }\end{array}$ \\
\hline Understanding & Instructors exert effort to understand and adjust to the limitations of students. \\
\hline Focused & $\begin{array}{l}\text { Instructors exert effort in simplifying lessons for maximum understanding of } \\
\text { students. }\end{array}$ \\
\hline Clear & $\begin{array}{l}\text { Instructors exert effort in making sure that students understand each lesson, } \\
\text { requirements, policies and exams clearly. }\end{array}$ \\
\hline Organized & $\begin{array}{l}\text { Instructors present topics using a certain flow of information that is easily } \\
\text { understandable to students. }\end{array}$ \\
\hline Understandable & $\begin{array}{l}\text { Instructors use a language that is understandable to all students. Instructors } \\
\text { accent do not affect students understanding of the lesson. }\end{array}$ \\
\hline Helpful & Instructors make sure that students understand the lessons in class. \\
\hline
\end{tabular}

\section{Cool Type}

\begin{tabular}{|l|l|}
\hline Characteristics & \multicolumn{1}{c|}{ Behavioral Manifestations } \\
\hline Flexible & $\begin{array}{l}\text { Instructors are not strict with absences and "late incurrence" of students in } \\
\text { class. }\end{array}$ \\
\hline Patient & Instructors are not irritated when students come to class late. \\
\hline
\end{tabular}

D. Academician Type

\begin{tabular}{|l|l|}
\hline \multicolumn{1}{|c|}{ Characteristics } & \multicolumn{1}{c|}{ Behavioral Manifestations } \\
\hline Professional & $\begin{array}{l}\text { Instructors are educated with higher degree and teach subjects from their own } \\
\text { field. }\end{array}$ \\
\hline Knowledgeable & Instructors have PhDs. \\
\hline Qualified & Instructors do have high qualifications like PhDs and degrees of specialization \\
\hline
\end{tabular}

\section{E. Techie Type}

\begin{tabular}{|l|l|}
\hline \multicolumn{1}{|c|}{ Characteristics } & \multicolumn{1}{|c|}{ Behavioral Manifestations } \\
\hline Professional & Instructors present lessons in a simple manner with the use of technologies. \\
\hline Knowledgeable & Instructors are confident in explaining their lesson with the use of technologies. \\
\hline Communicative & $\begin{array}{l}\text { Instructors use several means to communicate with students like SMS, } \\
\text { webmail, and portal. }\end{array}$ \\
\hline
\end{tabular}

\section{F. Non-Biased Type}

\begin{tabular}{|l|l|}
\hline \multicolumn{1}{|c|}{ Characteristics } & \multicolumn{1}{|c|}{ Behavioral Manifestations } \\
\hline Respectful & Instructors respect religion and culture of every student. \\
\hline Open minded & $\begin{array}{l}\text { Instructors recognize differences in abilities and cultures and adjust } \\
\text { accordingly. }\end{array}$ \\
\hline
\end{tabular}

